\title{
Phospholipase D affects translocation of NPR1 to the nucleus in Arabidopsis thaliana
}

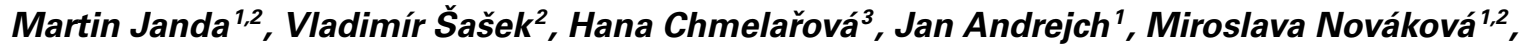 Jana Hajšlová ${ }^{3}$, Lenka Burketová $^{2}$ and Olga Valentová ${ }^{*}$}

${ }^{1}$ Department of Biochemistry and Microbiology, University of Chemistry and Technology Prague, Prague, Czech Republic

${ }^{2}$ Laboratory of Pathological Plant Physiology, Institute of Experimental Botany AS CR, Prague, Czech Republic

${ }^{3}$ Department of Food Analysis and Nutrition, University of Chemistry and Technology Prague, Prague, Czech Republic

\section{Edited by:}

Loreto Holuigue, Pontificia

Universidad Católica de Chile, Chile

Reviewed by:

Günther F. E. Scherer, Leibniz

Universität Hannover, Germany

Mats X. Andersson, University of

Gothenburg, Sweden

\section{*Correspondence:}

Olga Valentová, CSc., Laboratory of Plant Biochemistry, Department of

Biochemistry and Microbiology,

University of Chemistry and

Technology Prague, Technická 5,

Prague 6 - Dejvice, 16628, Czech

Republic

e-mail: olga.valentova@vscht.cz
Phytohormone salicylic acid (SA) is a crucial component of plant-induced defense against biotrophic pathogens. Although the key players of the SA pathway are known, there are still gaps in the understanding of the molecular mechanism and the regulation of particular steps. In our previous research, we showed in Arabidopsis suspension cells that $n$-butanol, which specifically modulates phospholipase $D$ activity, significantly suppresses the transcription of the pathogenesis related $(P R-1)$ gene, which is generally accepted as the SA pathway marker. In the presented study, we have investigated the site of $n$-butanol action in the SA pathway. We were able to show in Arabidopsis plants treated with SA that $n$-butanol inhibits the transcription of defense genes (PR-1, WRKY38). Fluorescence microscopy of Arabidopsis thaliana mutants expressing 35S::NPR1-GFP (nonexpressor pathogenesis related 1) revealed significantly decreased nuclear localization of NPR 1 in the presence of $n$-butanol. On the other hand, $n$-butanol did not decrease the nuclear localization of NPR1 in 35S::npr1C82A-GFP and 35S::npr1C216A-GFP mutants constitutively expressing NPR1 monomers. Mass spectrometric analysis of plant extracts showed that $n$-butanol significantly changes the metabolic fingerprinting while $t$-butanol had no effect. We found groups of the plant metabolites, influenced differently by SA and $n$-butanol treatment. Thus, we proposed several metabolites as markers for $n$-butanol action.

Keywords: $n$-butanol, NPR1, salicylic acid, phospholipase D, signaling, PR-1, metabolome

\section{INTRODUCTION}

The resistance of plants to pathogens relies on a sophisticated immune system comprising an orchestra of defense mechanisms. The efficiency is highly dependent on the speed of the process starting with pathogen recognition and resulting in the expression of appropriate defense proteins.

Salicylic acid (SA) is a crucial phytohormone involved in the defense response mostly to biotrophs (Glazebrook, 2005; Tsuda et al., 2008; Tsuda and Katagiri, 2010), but several reports on the defense against necrotrophs also exist (Novakova et al., 2014). The key enzyme in SA biosynthesis is isochorismate synthase (ICS; EC 5.4.4.2) that catalyses the conversion of chorismate into isochorismate. ICS is encoded by two genes in Arabidopis thaliana. This pathway has been shown to be the dominant SA biosynthetic pathway in response to attack by pathogenic bacteria, contributing to approximately $90 \%$ of total SA, with most ICS activity attributed to ICS1 and ICS2, which ICS2 plays only a marginal role (Wildermuth et al., 2001). SA is catabolized in

Abbreviations: NPR1, nonexpressor of pathogenesis related 1; PA, phosphatidic acid; PDK1, 3-phosphoinositide-dependent protein kinase 1; PI4K, phosphatidylinositol 4-kinase; PI4P, phosphatidyl inositol 4-phosphate; PIP $_{2}$, phosphatidylinositol 4,5-bisphosphate; PR, patogenesis related; PLD, phospholipase D; SA, salicylic acid. infected and senescing plants by the recently found enzyme salicylic acid-3-hydroxylase ( $\mathrm{S} 3 \mathrm{H})$, which catalyzes conversion of SA to 2,3-dihydroxybenzoic acid (2,3-DHBA; gentisic acid) and thus regulates the level of SA in plants (Zhang et al., 2013). The SA mode of action has been intensively studied for more than 20 years (Vlot et al., 2009). The crucial component of the SA pathway is a nonexpressor of pathogenesis related 1 (NPR1) protein (Cao et al., 1994). It was shown that NPR1 influences transcription of $\sim 90 \%$ of the SA dependent defense genes (Wang et al., 2005; Blanco et al., 2009). In cytosol, NPR1 occurs as an oligomer. Increased amounts of SA cause the monomerization of the NPR1 oligomer due to the change of the redox state in the plant cell (Mou et al., 2003). Thereafter, the NPR1 monomer is translocated to the nucleus where the NPR1 monomers bind to the TGA transcription factors followed by their direct binding to the as- 1 (activation sequence 1) cis-regulatory element that is present in the promoters of $P R$ (pathogenesis related) genes, thus activating their expression (Jakoby et al., 2002). The PR-1 gene is generally accepted as the marker for SA signaling. The monomeric NPR1, in the nucleus, is continuously degraded by proteasome, a process which plays a dual function in the induction of transcription of the SA related genes (e.g., PR-1) (Wang et al., 2005; Spoel et al., 2009). Proteasome degradation lowers the amount of NPR1 in 
the nucleus, but considering that newly formed NPR1 is needed for the induction of $P R-1$ transcription, the proteasome plays a key role in the regulation of NPR1 turnover (Spoel et al., 2009). Recently, a crucial step forward was made in the understanding of SA awareness; the long sought after SA receptor was probably found. Xinnian Dong's group showed that NPR3 and NPR4 (two orthologs of NPR1) have a binding affinity to SA. Interestingly, the binding affinity of NPR4 is much higher than that of NPR3, but this property is crucial for the correct regulation of NPR1 degradation and SA awareness (Fu et al., 2012).

Currently, it seems more obvious that the SA pathway is connected with the phospholipid signaling system (Janda et al., 2013), but the details are unknown. One of the key players of the phospholipid signaling in plants is phosphatidic acid (PA), produced by the action of phospholipase $\mathrm{C}$ and DAG kinase or directly by phospholipase D (PLD) (EC 3.1.4.4). PLD activity is specifically modulated by $n$-butanol due to the unique transphosphatidylation reaction catalyzed by this enzyme (Yang et al., 1967; Munnik et al., 1995). In the presence of low concentrations of primary alcohols, the phosphatidate moiety is preferentially transferred to the alcohol hydroxyl group rather than to the water molecule and the products of this reactionphosphatidylalcohols are metabolically stable (Liscovitch et al., 2000). PLD occurs in A. thaliana in 12 isoforms with distinct biochemical and structural properties (Pleskot et al., 2012). Activation or increased expression of PLD isoforms after infection was shown in rice (Young et al., 1996; Lee et al., 1997; McGee et al., 2003) and A. thaliana (De Torres Zabela et al., 2002). The treatment with SA increased the PA level or PLD activity in A. thaliana, Brassica napus and soybean (Profotova et al., 2006; Kalachova et al., 2012; Rainteau et al., 2012). Zhao et al. (2013) investigated the role of AtPLD $\beta 1$ in defense responses to bacterial pathogens. PLD $\beta 1$-deficient plants were less susceptible to Pseudomonas syringae and the transcription of SA responsive genes rose in infected plants compared to the wild-type infected plants (Zhao et al., 2013). Krinke et al. (2009) described that in A. thaliana suspension cells, $n$-butanol blocked the $P R-1$ transcription in the presence of SA. However, the mechanism of $\mathrm{PLD} / \mathrm{PA}$ involvement in SA signaling remains unclear.

This work provides evidence that $n$-butanol, the most effective primary alcohol modulating the activity of PLD, is involved in the regulation of $P R-1$ transcription in the seedlings of $A$. thaliana. We show also that its action proceeds or participates in the process of NPR1 transfer to the nucleus. The non-targeted metabolomic fingerprinting provides evidence that $n$-butanol has a substantial impact on metabolome whereas $t$-butanol remains ineffective.

\section{MATERIALS AND METHODS PLANT MATERIAL}

Seedlings of $A$. thaliana ecotype Col-0 (WT), and transgenic plants 35S::NPR1-GFP, 35S::npr1C82A-GFP, 35S::npr1C216AGFP (Kinkema et al., 2000; Mou et al., 2003) were grown in 24-well plates in $400 \mu \mathrm{L}$ of MS liquid medium (Clay et al., 2009) for 10 days in a cycle of $10 \mathrm{~h}$ days $\left(120 \mu \mathrm{E} \mathrm{m}^{-2} \mathrm{~s}^{-1}, 22^{\circ} \mathrm{C}\right)$ and $14 \mathrm{~h}$ nights $\left(22^{\circ} \mathrm{C}\right)$ at $70 \%$ relative humidity. MS liquid medium in the wells was changed on the 7 th day.

\section{CHEMICAL TREATMENTS}

The plants were treated directly in the wells of plates by changing the growing medium for the chemical-containing medium. 10 -day-old seedlings were treated for $6 \mathrm{~h}$ with $50 \mu \mathrm{M}$ and $250 \mu \mathrm{M}$ salicylic acid sodium salt (Sigma; NaSA), 0.1 and $1 \% n$-butanol (Sigma) or $t$-butanol (Penta).

\section{GENE TRANSCRIPTION ANALYSIS}

The whole seedlings from three wells were immediately frozen in liquid nitrogen. The tissue was homogenized in tubes with $1 \mathrm{~g}$ of $1.3 \mathrm{~mm}$ silica beads using a FastPrep-24 instrument (MP Biomedicals, CA, USA). RNA isolation and reverse transcription were performed as previously described (Sasek et al., 2012). An equivalent of $6.25 \mathrm{ng}$ of RNA was loaded into a $10 \mu \mathrm{l}$ reaction with qPCR mastermix EvaLine-E1LC (GeneOn, Ludwigshafen am Rhein, Germany). The reactions were performed in polycarbonate capillaries (Genaxxon, Ulm, Germany) and a LightCycler 1.5 (Roche). The following PCR program was used for PCR assays: $95^{\circ} \mathrm{C}$ for $10 \mathrm{~min} ; 45$ cycles: $95^{\circ} \mathrm{C}$ for $10 \mathrm{~s}, 55^{\circ} \mathrm{C}$ for $10 \mathrm{~s}$, and $72^{\circ} \mathrm{C}$ for $10 \mathrm{~s}$; finished with a melting curve analysis. Threshold cycles and melting curves were calculated using LightCycler Software 4.1 (Roche). Alternatively, the LightCycler ${ }^{\circledR} 480$ SYBR Green I master kit was used. The reactions were performed in the LightCycler ${ }^{\circledR}$ 480 Multiwell Plate 96 white. The following PCR program was used for PCR assays: $95^{\circ} \mathrm{C}$ for $10 \mathrm{~min}$; 45 cycles: $95^{\circ} \mathrm{C}$ for $20 \mathrm{~s}$, $55^{\circ} \mathrm{C}$ for $20 \mathrm{~s}$, and $72^{\circ} \mathrm{C}$ for $10 \mathrm{~s}$; finished with a melting curve analysis. The threshold cycles and melting curves were calculated using LightCycler Software 4.2 (Roche). The relative transcription was calculated with the efficiency correction and normalization (Czechowski et al., 2005). The primers were designed using PerlPrimer v1.1.17 (Marshall, 2004). The list of A. thaliana genes and corresponding accession numbers and primers follows: SAND, AT2G28390, FP: 5'CTG TCT TCT CAT CTC TTG TC 3', RP: $5^{\prime}$ TCT TGC AAT ATG GTT CCT G 3', PR-1, AT2G14610, FP: 5' AGT TGT TTG GAG AAA GTC AG 3', RP: 5' GTT CAC ATA ATT CCC ACG A, S3H, AT4G10500, FP: 5'GGA TGA TAA ATG GGT CGC T 3', RP: 5'TGT TTA CTA CGG CTC TAT GG 3'; WRKY38, AT5G22570, FP: 5'GCC CCT CCA AGA AAA GAA AG 3', RP: 5' CCT CCA AAG ATA CCC GTC GT 3', ICS1 AT1G74710 FP: 5'GCA AGA ATC ATG TTC CTA CC 3', RP: 5'AAT TAT CCT GCT GTT ACG AG 3'.

\section{CONFOCAL MICROSCOPY}

The slide with seedlings was positioned onto an inverted platform (with a cover slip at the bottom) of the confocal laser scanning Zeiss LSM 5 DUO microscope. The GFP fluorescence was excited by the $488 \mathrm{~nm}$ line of a laser, the DAPI fluorescence was excited by the $405 \mathrm{~nm}$ line. The epidermal cells were viewed using an Zeiss Plan-Apochromat 20x/0,8 objective. The emitted light was captured using the HFT405/488 beam splitter and a 505-550 nm or $420-480 \mathrm{~nm}$ band-pass filter, respectively. Image analysis was performed using the software APS Asess 2.0.

\section{METABOLOMIC SCREENING}

The extraction procedure was modified according to Vaclavik et al. (2013). Whole seedlings from three independent wells were immediately frozen using liquid nitrogen. Six independent 
samples for one type of treatment were prepared for one biological replicate. $150-250 \mathrm{mg}$ of plant tissue was homogenized in tubes with $1 \mathrm{~g}$ of $1.3 \mathrm{~mm}$ silica beads using a FastPrep-24 instrument (MP Biomedicals,CA, USA). After the addition of $700 \mu \mathrm{L}$ of methanol (p.a.; PENTA), the plant tissue was homogenized again. The silica beads were washed once with $700 \mu \mathrm{L}$ methanol and both extracts were combined. The samples were kept on ice during the extraction. Prior to instrumental analysis, the samples were stored in a dark and dry environment at $-70^{\circ} \mathrm{C}$. The UHPLC-Q-TOF-MS analyses were performed using an Acquity Ultra-Performance LC system coupled to a Synapt G2 high definition mass spectrometer (Waters, USA). The LC separation was performed by an Acquity UPLC ${ }^{\circledR}$ HSS T3 column $(100 \times 1.8 \mathrm{~mm}$, $1.7 \mu \mathrm{m}$ particle size; Waters, USA). The gradient elution was used with the mobile phases consisting of (A) $0.1 \%$ formic acid in Milli-Q water and (B) $0.1 \%$ formic acid in methanol.

The Synapt G2 HD instrument was operated in the negative electrospray ionization (ESI) mode. The parameter settings used during the measurements were as follows: capillary voltage $(-700 \mathrm{~V})$, cone voltage $(-25 \mathrm{~V})$, source temperature $\left(120^{\circ} \mathrm{C}\right)$, and desolvation temperature $\left(350^{\circ} \mathrm{C}\right)$. Nitrogen was used as both desolvation and cone gas at a flow rate of 800 and $10 \mathrm{~L} / \mathrm{h}$, respectively. Both full MS and MS/MS fragmentation mass spectra were acquired at a rate of two spectra per second in the range $m / z 50-1000$. In order to diminish any possible time dependent changes in the UHPLC-MS chromatographic fingerprints, the sequence of the samples was randomized and one sample was chosen as a quality control sample, which was injected after every set of 20 samples. The MassLynx 4.1 software (Waters, USA) was used for data acquisition and the MarkerLynx software (Waters, USA) was used for data mining and processing. The software SIMCA (v. 13.0, Umetrics, Sweden) was then used for data processing based on Principal Components Analysis (PCA).

\section{DATA EVALUATION}

Values are expressed as means \pm standard error (SE). For statistical analysis, Student's $t$-test or One-Way ANOVA followed by Fisher's Least-Significant-Difference (LSD) were used as appropriate, with a value $P<0.05$ considered significant for mean differences using STATGRAPHICS ${ }^{\circledR}$ Centurion XVII software.

\section{RESULTS \\ n-BUTANOL ALTERS SALICYLIC ACID RELATED GENES TRANSCRIPTION}

The increased levels of SA or exogenous treatment with this phytohormone activates the signaling pathway resulting in the transcription of defense related genes (e.g., pathogenesis related). The generally accepted marker of SA signaling is the $P R-1$ gene. In order to examine possible role of PLD/PA in this process, we co-treated 10-day-old seedlings of A. thaliana with both SA
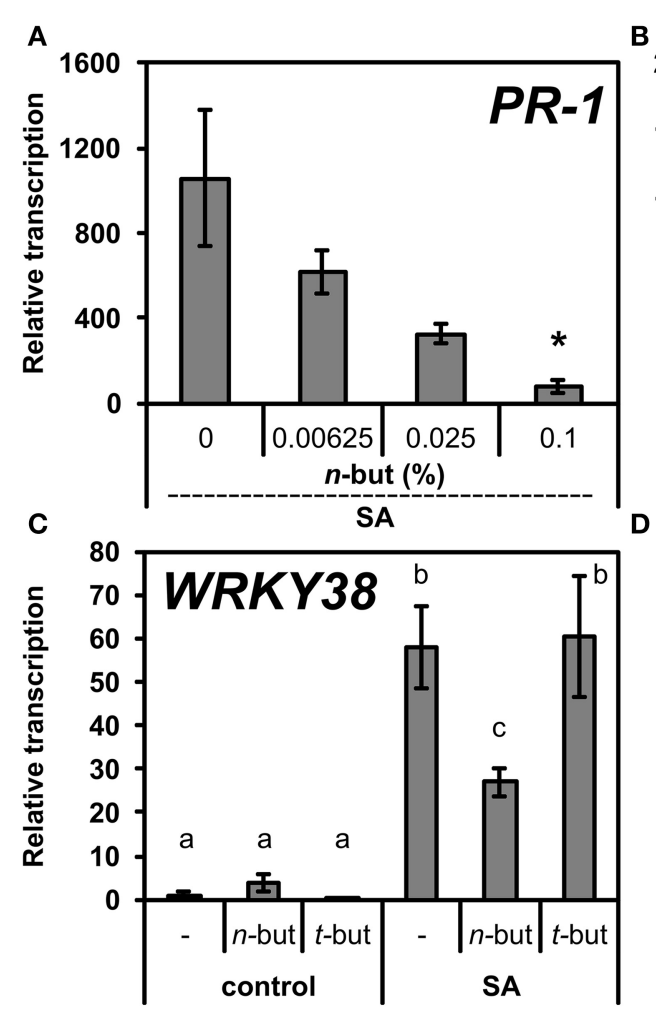

FIGURE 1 | Effect of $\boldsymbol{n}$-butanol on SA related genes transcription. (A) Ten-day-old $A$. thaliana seedlings were treated for $6 \mathrm{~h}$ with $50 \mu \mathrm{M}$ NaSA (SA) and $0.00625,0.025,0.1 \% n$-butanol. (B-D) 10-day-old $A$. thaliana seedlings were treated for $6 \mathrm{~h}$ with $0.1 \% n$-butanol and $0.1 \% t$-butanol or with $50 \mu \mathrm{M}$ NaSA together with the above mentioned alcohols. Pure MS was used as a
B

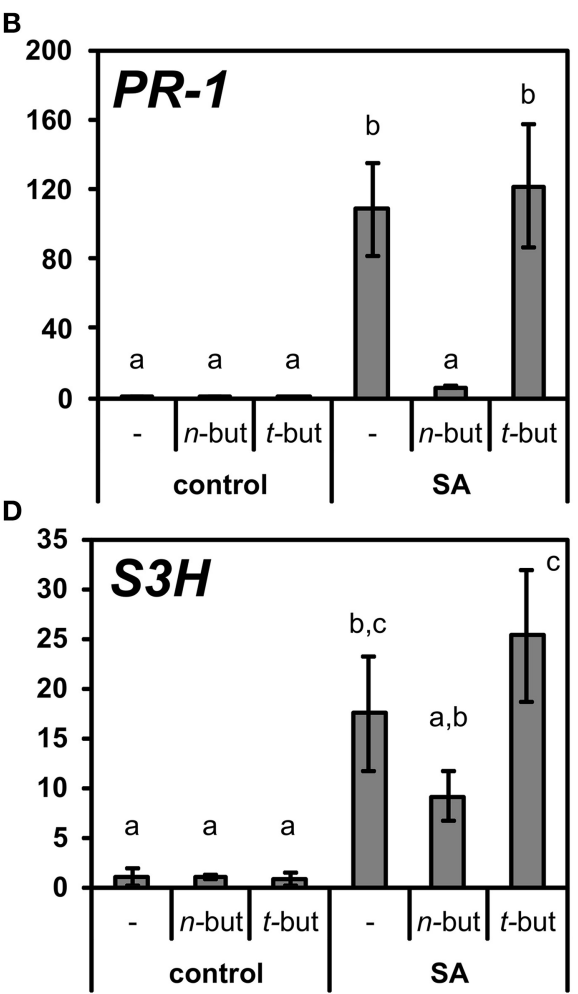

control. Error bars represent SE from three biological repeats. Asterisks indicate statistically significant differences compared to NaSA-treated plants without $n$-butanol ( ${ }^{*} P<0.05$, Student's $t$-test) for (A). Different letters indicate significant differences $(P<0.05)$ and were calculated with One-Way ANOVA and Fisher's LSD test. Transcription was normalized to a reference gene SAND. 
and increasing concentrations of $n$-butanol. The SA induced $P R$ 1 transcription was decreased in the presence of $n$-butanol in a strongly dose-dependent manner (Figure 1A). Contrarily, the $t$-butanol showed no effect on the $P R-1$ transcription (Figure 1B).

We also examined the effect of both alcohols on the transcription of other SA related genes, WRKY38 and $S 3 H$, both encoding proteins with different functions. While the PR-1 protein is responsible for a direct antimicrobial effect as the end product of SA pathway, WRKY38 is a transcription factor which negatively regulates $P R-1$ transcription, but it is NPR1 dependent (Kim et al., 2008). S3H is an enzyme responsible for the conversion of SA to a less biologically active compound, gentisic acid (Zhang et al., 2013). WRKY38 and S3H transcriptions were not as significantly blocked as $P R-1$ transcription. The relative transcription of WRKY38 decreased only two times and even less in the case of $S 3 H$ (Figures 1B-D). Also, the dose dependence of the $n$-butanol effect on the transcription of these two genes was far less apparent (Supplemental Figure S1).

\section{n-BUTANOL AFFECTS NPR1 ACCUMULATION IN NUCLEUS}

We further intended to take a closer look at the site of $n$-butanol action in the SA signaling pathway. To decipher, we used 35S::NPR1-GFP A. thaliana transgenic plants. It was confirmed earlier that the treatment of these mutants with 2,6dichloroisonicotinic acid (INA), a functional analog of SA, causes monomerization of NPR1, which is afterwards accumulated in the plant cell nucleus (Mou et al., 2003). We treated 10-dayold 35S::NPR1-GFP A. thaliana seedlings with $250 \mu \mathrm{M}$ NaSA and observed a significant increase of fluorescence in the nuclei (Figures 2A,B), the same effect was described for INA treatment. The accumulation of 35S::NPR1-GFP in the nuclei in the presence of NaSA decreased after addition of $1 \% n$-butanol (Figures 2A,B). When $t$-butanol was applied as a negative control, no effect on the 35S::NPR1-GFP accumulation in the nuclei was observed (Figures 2A,B). n-butanol alone decreased the basal accumulation of NPR1 in the nuclei in the control plants, while no effect was observed for $t$-butanol. The localization of NPR1-GFP in the nuclei was verified by DAPI staining (Supplemental Figure S2). All these results correlate with the aforementioned PR-1 transcription analysis (Figure 1B). Consequently, we wanted to examine whether the decreased amount of NPR1 in the nucleus caused by $n$-butanol is due to the higher actvity of proteasomes in NPR1 degradation (Spoel et al., 2009). For this experiment, we used 35S::npr1C82A-GFP and 35S::npr1C216A-GFP seedlings expressing constitutively monomerized NPR1, which is overaccumulated in the nucleus (Mou et al., 2003). The treatment of these mutants with $0.1 \%$ and $1 \% n$-butanol did not decrease the accumulation of NPR1 in the nuclei (Figure 3). This experiment also provides evidence that $n$-butanol does not influence fluorescence intensity.

\section{n-BUTANOL INDUCES ICS1 TRANSCRIPTION}

Zhang et al. (2010) showed that nuclear localization of NPR1 is required for SA accumulation, ICS1 transcription and SA tolerance. When NPR1 was retained in the cytoplasm, plants accumulated higher levels of ICS1 transcripts compared to the wild type. Based on this, we measured the transcription

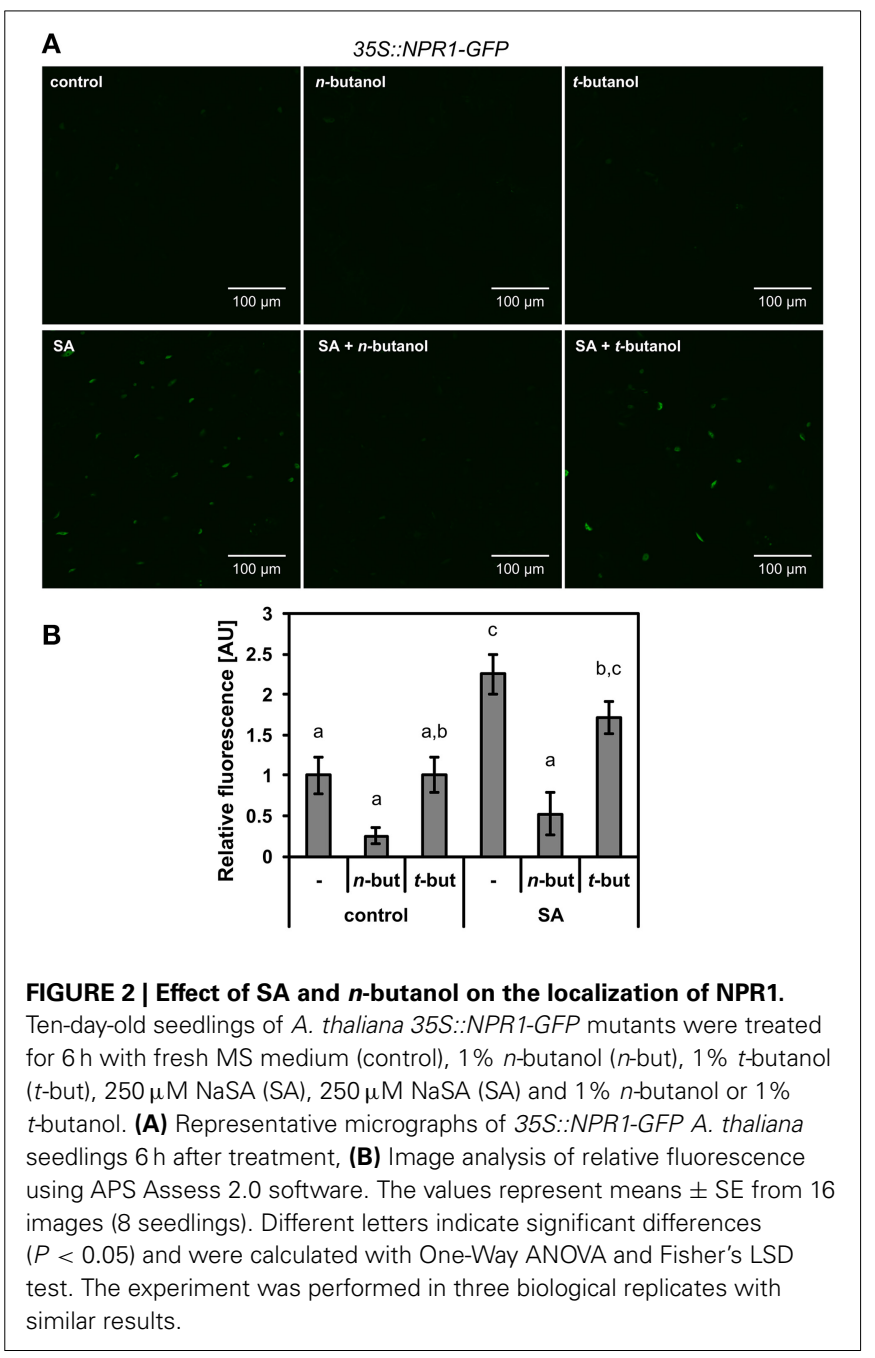

of ICS1 upon the addition of the $n$-butanol treatment and as expected, $n$-butanol induced ICS 1 transcription in a dosedependent manner (Figure 4A), while $t$-butanol had no effect (Figure 4B). These results support our suggestion that $n$-butanol inhibits the translocation of NPR1 to the nucleus. Accordingly, we also found that the ICS1 transcription in 35S::npr1C82AGFP and 35S::npr1C216-GFP mutants were significantly decreased but $n$-butanol treatment partially reverted this effect (Figure 4C).

\section{n-BUTANOL CAUSES CHANGES IN A. THALIANA METABOLOME}

As the accumulation of SA leads to the massive reprogramming of the plant transcriptome, it was obviously accompanied by significant changes in the whole metabolome. We investigated these changes in plants treated with SA and $n$-butanol to test if we could reveal compounds involved in the SA/phospholipid signaling pathway.

The principle component analysis (PCA) represents a highly useful and widely employed tool for the interpretation of complex data sets generated by several modern instruments including mass spectrometry. In our study, PCA was employed to explore alterations in the metabolomes of differently treated A. thaliana 

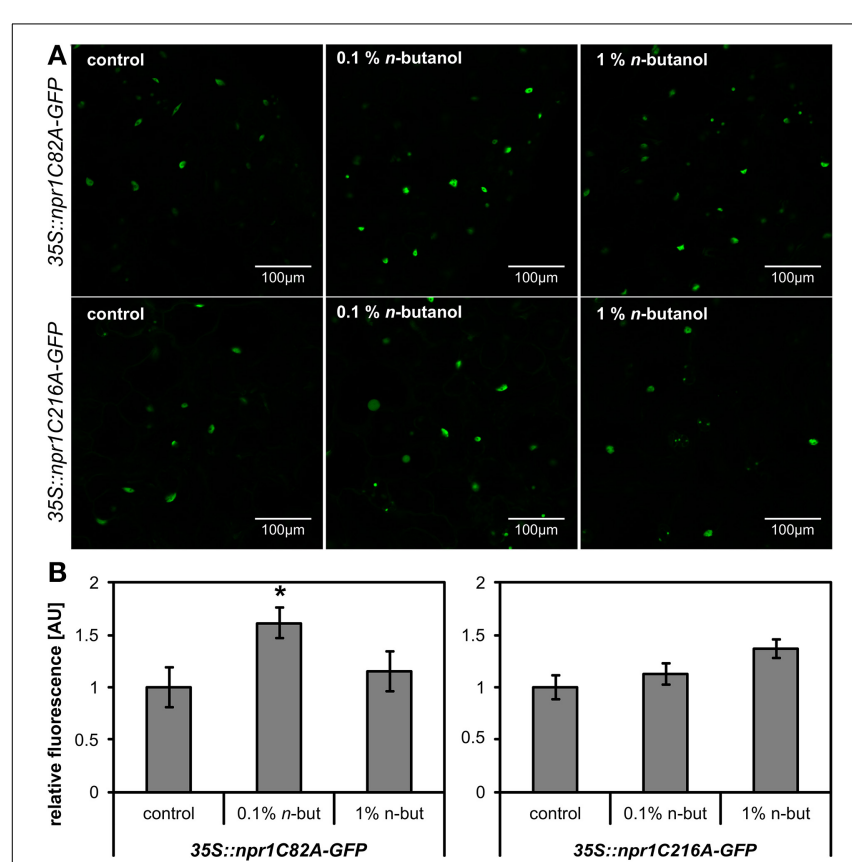

FIGURE 3 | Effects of $n$-butanol on the accumulation of NPR1 in the nuclei of Arabidopsis thaliana mutants constitutively expressing monomers of NPR1. Ten-day-old seedlings of 35S::npr1C82A-GFP and 35S::npr1C216A-GFP A. thaliana mutants were treated $6 \mathrm{~h}$ with fresh MS medium (control), $0.1 \% n$-butanol and $1 \% n$-butanol (n-but). (A) Representative images of 35S::npr1C82A-GFP and 35S::npr1C216A-GFP $A$. thaliana seedlings $6 \mathrm{~h}$ after treatment, (B) Image analysis of relative fluorescence using APS Assess 2.0 software. The values represent means \pm SE from 12 images (6 seedlings). Asterisks indicate statistically significant differences compared to the control, non-treated plants ${ }^{*} P<$ 0.05 , Student's $t$-test). The experiment was performed in two biological replicates with similar results.

samples measured by LC-MS. As shown in Figure 5, there was a significant difference in the metabolomic fingerprints of samples treated with $n$-butanol (right side of the PCA plot) and untreated ones (left side of the PCA plot). The samples treated with SA were clearly differentiated (bottom part of the PCA plot) from the untreated samples (top part of the PCA plot). The list of the most distinct markers (ions recovered from the LC-MS records) is summarized in Table 1. Obviously, SA and its metabolite SA hexoside are typical markers for the samples treated with SA. Unfortunately, the identification of markers present in $n$-butanol treated plants was mostly unsuccessful, mainly due to their high $\mathrm{m} / z$ values resulting in many possible elemental formulas and also due to the limited information about the changes induced by $n$ butanol in the metabolism. Important observations were that the $t$-butanol treated samples did not differentiate from the untreated samples and also that $t$-butanol had no effect on the SA treated samples (Figure 5).

We identified 114 metabolites, from which 61 were statistically $(P=0.05$; two tailed Student's $t$-test) changed at least in one of the used treatments (Figure 6). Based on the response to treatment, we were able to divide the metabolites into six groups (Figure 6) according to whether they were induced or suppressed by SA, $n$-butanol or both chemicals together.

\section{DISSCUSSION}

Plant response to biotic stress mediated by the phytohormone SA is a fundamental process. It was shown that NPR1 protein is a crucial component of the SA signaling (Cao et al., 1994). The structural changes and localization of this protein in plant cells is responsible for the plant defense signaling (Kinkema et al., 2000). Whereas an oligomer form occurs in cytosol, the monomer, which is formed when SA level increases, is translocated to the nucleus (Mou et al., 2003), where it binds to the TGA transcription factors and induces a transcription of the most of SA related genes (Zhang et al., 1999; Wang et al., 2005). NPR1 nuclear localization is responsible for regulation of plant tolerance to SA, a negative regulation of ICS1 transcription and leads to SA accumulation (Zhang et al., 2010). Thus, NPR1 is really a master regulator of the SA signaling pathway although the NPR1 independent pathway also exists (Janda and Ruelland, 2014). Nevertheless, there are still gaps in the knowledge of the regulation of SA signaling needing to be filled in.

\section{n-BUTANOL AND NPR1 DEPENDENT SA SIGNALING PATHWAY}

In our study, we have shown that $n$-butanol is a molecule with a high impact on the SA signaling pathway in A. thaliana seedlings. $n$-butanol has been for a long time accepted by the "PLD community" as a modulator of PLD activity due to its preference for primary alcohols as substrates (Yang et al., 1967; Munnik et al., 1995). Potocky et al. (2014) recently provided excellent evidence that $n$-butanol alters the concentration of PA on the pollen tube's plasma membrane in vivo. $n$-butanol was used to establish the PLD/PA signaling connection with G proteins, ABA triggered germination, primary root elongation, hypocotyl length, cotyledon expansion, inhibition of pollen tube germination and growth, proline accumulation, actin cytoskeleton rearangement and microtubule reorganization (Munnik et al., 1995; Ritchie and Gilroy, 1998; Dhonukshe et al., 2003; Gardiner et al., 2003; Potocky et al., 2003; Thiery et al., 2004; Motes et al., 2005; Pleskot et al., 2010, 2014). We would like to mention that it is necessary to keep in mind the possibility that the effect of $n$-butanol is not so specific as was mentioned by Hirase et al. (2006), who observed that $n$-butanol induced the depolymerization of microtubules. Although the use of $t$-butanol, as a control, can serve as convincing proof.

In our study, the treatment of $A$. thaliana seedlings with $n$ butanol rapidly decreased $P R-1$ transcription in the presence of SA and this effect is clearly dose dependent (Figures 1A,B). The effect on the transcription of WRKY38 and $S 3 H$ was much less pronounced (Figures 1C,D) but in the case of WRKY38 the decrease was significant (more than two times) and so the transcription pattern seems similar to $P R$-1. It is not surprising, as the transcription of WRKY38 is also NPR1 dependent. Our results are in agreement with the results obtained by Krinke et al. (2009) in A. thaliana suspension cells. $n$-butanol did not have a significant effect on $\mathrm{S} 3 \mathrm{H}$ transcription. $\mathrm{S} 3 \mathrm{H}$ is responsible for a conversion of SA, therefore its transcription should be induced immediately by higher levels of SA and the signaling events downstream to SA can have only a minor effect on $S 3 H$ transcription (Figure 1D). In fact, the connection between the $\mathrm{S} 3 \mathrm{H}$ effect and NPR1 has not yet been described in detail. 

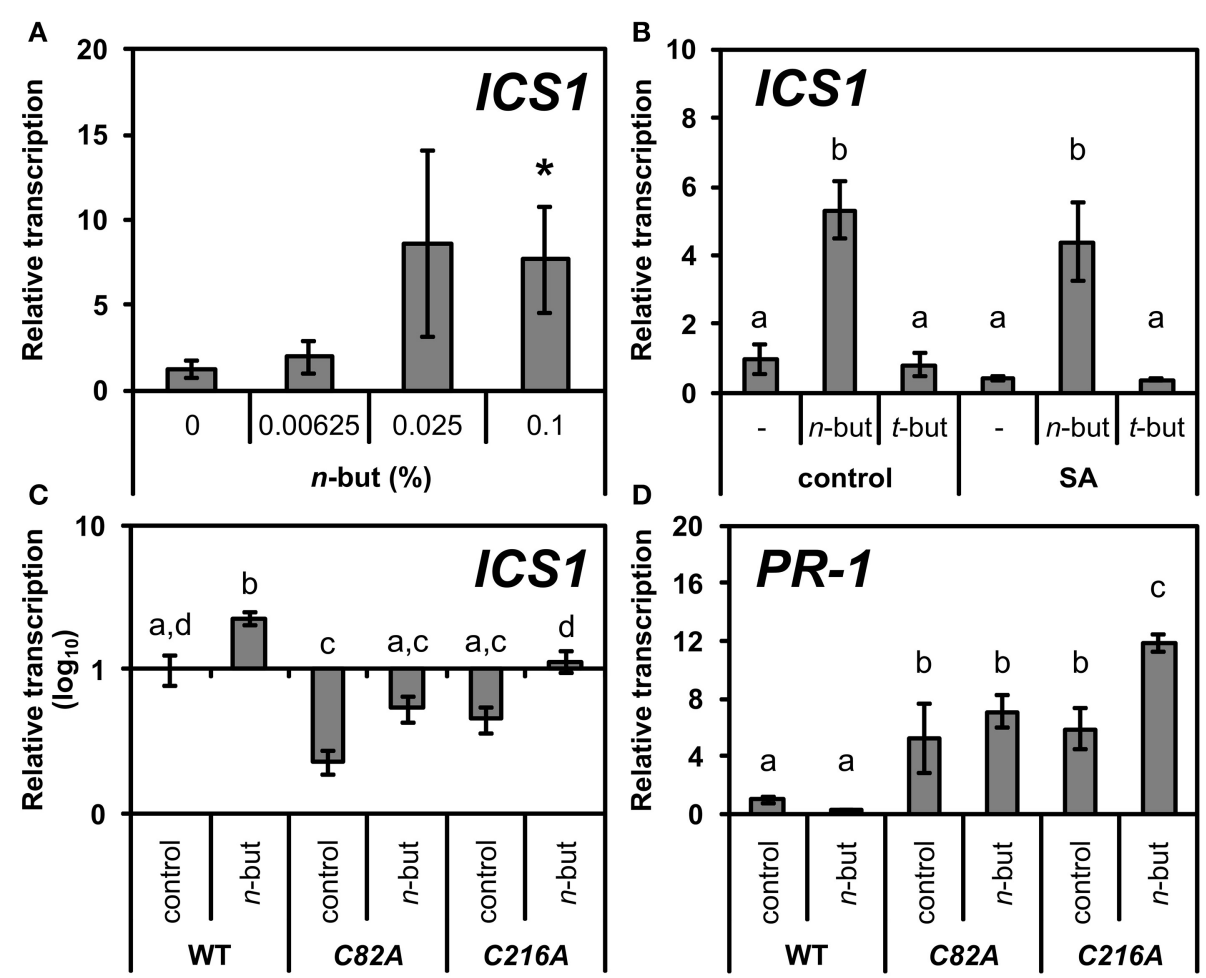

FIGURE 4 | Transcription of ICS1 and PR-1 in wild type and mutants of Arabidopsis thaliana constitutively expressing monomeric NPR1 in the presence of $\boldsymbol{n}$-butanol. (A) Ten-day-old A. thaliana seedlings (wt) were treated for $6 \mathrm{~h}$ with $50 \mu \mathrm{M}$ NaSA (SA) and $0.00625,0.025,0.1 \% n$-butanol. (B) Ten-day-old $A$. thaliana seedlings (wt) were treated for $6 \mathrm{~h}$ with $0.1 \% n$-butanol and $0.1 \%$ $t$-butanol or with $50 \mu \mathrm{M} \mathrm{NaSA}$ (SA) together with the above mentioned alcohols. (C,D) Ten-day-old seedlings of 35S::npr1C82A-GFP (C82A) and
35S::npr1C216A-GFP (C216A) A. thaliana mutants were treated for $6 \mathrm{~h}$ with fresh MS medium (control) or MS with $0.1 \% n$-butanol. Error bars represent SE from three independent repeats. Asterisks indicate statistically significant differences compared to control, non-treated plants $\left({ }^{*} P<0.05\right.$, Student's $t$-test) for $(\mathbf{A})$. Different letters indicate significant differences $(P<0.05)$ and were calculated with One-Way ANOVA and Fisher's LSD test for (B-D). The ICS1 and PR-1 transcription was normalized to a reference gene SAND.

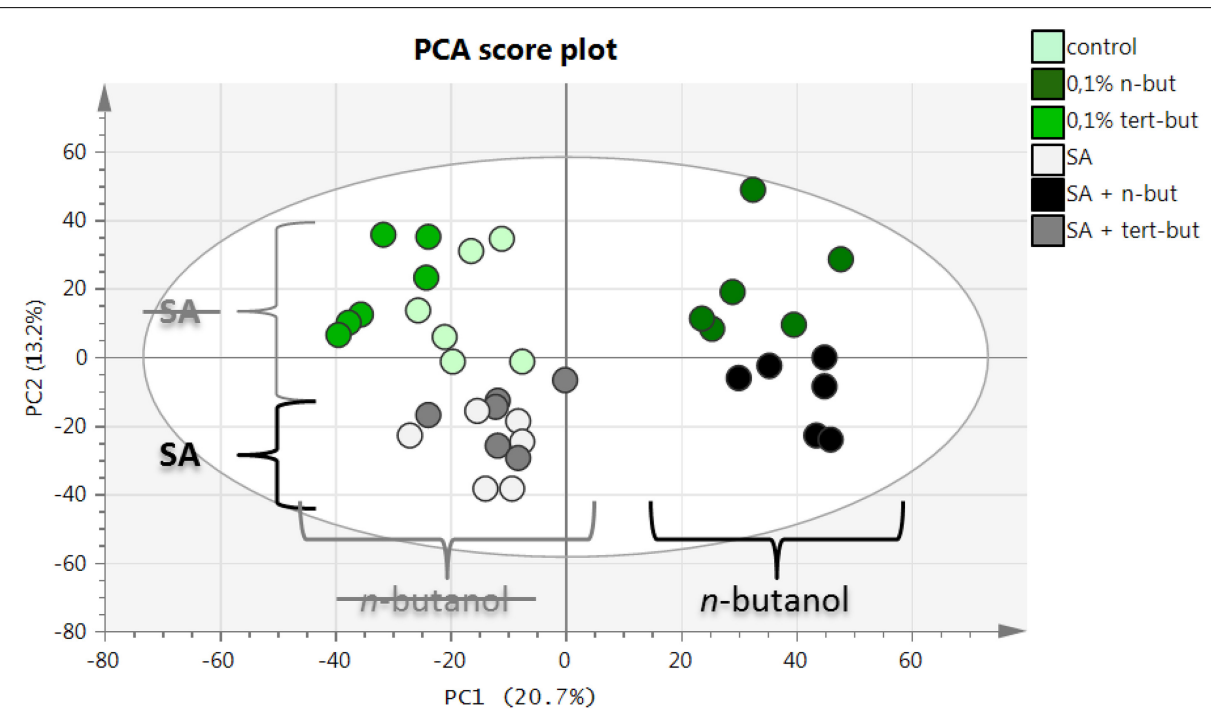

FIGURE 5 | PCA score plot for LC-ESI(-)-MS data of $\boldsymbol{n}$-butanol and salicylic acid metabolome in $\boldsymbol{A}$. thaliana. Ten-day-old $A$. thaliana seedlings were treated for $6 \mathrm{~h}$ with $0.1 \% n$-butanol or $0.1 \% t$-butanol or with $50 \mu \mathrm{M}$
NaSA (SA) together with the aformentioned alcohols. Fresh MS medium was used as a control. This experiment was done in three biological repeats with similar results. 
Table 1 | The most distinct metabolites (markers) of $\boldsymbol{A}$. thaliana seedlings.

\begin{tabular}{|c|c|c|c|c|c|c|}
\hline $\mathrm{m} / \mathbf{z}$ & RT (min) & Ion elemental Formula & Tentative identification & Ion & Mass error (ppm) & Marker of treatment \\
\hline 202.0714 & 1.61 & $\mathrm{C}_{8} \mathrm{H}_{12} \mathrm{NO}_{5}$ & N-Butyryl-L-aspartic acid & {$[\mathrm{M}-\mathrm{H}]-$} & 2.0 & n-but \\
\hline 295.1028 & 1.79 & $\mathrm{C}_{11} \mathrm{H}_{19} \mathrm{O}_{9}$ & $?$ & $?$ & 1.5 & n-but \\
\hline 299.0768 & 2.04 & $\mathrm{C}_{13} \mathrm{H}_{15} \mathrm{O}_{8}$ & Salicylic acid-hexoside & {$[\mathrm{M}-\mathrm{H}]-$} & 2.2 & SA \\
\hline 536.1651 & 0.69 & $?$ & $?$ & $?$ & $?$ & n-but \\
\hline
\end{tabular}

A deeper insight into the mode of action of $n$-butanol in SA signaling provided the experiment with 35S::NPR1-GFP A. thaliana mutants. We observed that effect of $n$-butanol is closely connected with the NPR1 localization in plant cells. In the 35S::NPR1-GFP plants, $n$-butanol blocks NPR1 accumulation in the nucleus in the presence of SA (Figure 2). This finding well corresponds with the suppressive effect of $n$-butanol on the transcription of $P R-1$. Zhang et al. (2010) showed that nuclear localization of NPR1 negatively regulates the transcription of the ICS1 gene. We observed that $n$-butanol induces the transcription of ICS1 (Figure 4), which supports the idea that $n$-butanol blocks translocation of monomeric NPR1 to the nucleus. It was reported that the proteasome degrades NPR1 monomers in the nucleus (Spoel et al., 2009). Based on that fact we used 35S::npr1C82A-GFP and 35S::npr1C216A-GFP mutants which constitutively express a higher amount of NPR1 monomers and also exhibit a higher accumulation of NPR1 in the nucleus (Mou et al., 2003). In these mutants, we investigated the effect of $n$-butanol. As $n$-butanol treatment revealed no effect on the nuclear localization of NPR1 in the 35S::npr1C82A-GFP and 35S::npr1C216A-GFP mutants (Figure 3), we can assume that $n$-butanol acts in the cytosol in the SA pathway before or during NPR1 translocation to the nucleus. $n$-butanol could either affect the transmission of the monomer from the cytosol to the nucleus e.g., by direct effect of $n$-butanol on the nucleopores or by active transport which can be mediated by PA. This mechanism was recently shown in the nuclear localization of the MYB transcription factor (Yao et al., 2013). Nevertheless, we cannot exclude the possibility that $n$-butanol acts upstream to NPR1 monomerization (Figure 8).

\section{PHOSPHOLIPIDS IN SA SIGNALING}

Based on the above mentioned observations, we would like to highlight the possible connection between the phospholipid signaling system and the SA pathway. SA treatment increased the PA level or the PLD activity in A. thaliana, B. napus. and soybean (Profotova et al., 2006; Kalachova et al., 2012, 2013; Rainteau et al., 2012). Krinke et al. (2009) showed in A. thaliana suspension cells that SA treatment led to a rapid increase of the PA level in vivo. We observed that the exogenous PA is capable of preventing the disruption of the actin cytoskeleton caused by SA (Matouskova et al., 2014). PLD and PA are not the only members of large phospholipid family involved in SA signaling. Interestingly, it was shown that SA treatment activates type-III phosphatidylinositol-4-kinase (PI4K), which is responsible for the formation of phosphatidylinositol-4-phosphate (PI4P) and phosphatidylinositol-4,5-bisphosphate $\left(\mathrm{PIP}_{2}\right)$ in $A$. thaliana suspension cells (Krinke et al., 2007). Recently, we showed that double knock-out mutation of two isoforms PI $4 \mathrm{~K} \beta 1 \beta 2$ triggers SA signaling, suggesting them to be negative regulators of SA signaling (Sasek et al., 2014). For more information about the connection between hormones and phospholipid signaling see the review (Janda et al., 2013).

The interest of importance is to find out the particular isoform(s) of PLD responsible for the effect of $n$-butanol. Based on this, we performed the in silico experiment to find the possible PLD isoforms involved in SA signaling (Figure 7). We investigated the transcription of all PLD isoforms in the publicly available database, Genevestigator (Hruz et al., 2008), in response to SA, BTH (benzothiadiazole; a functional analog of SA), EF-Tu, flg22, pep2 (well described PAMPs) triggering SA signaling. All studies, which we included to this analysis, were performed on the A. thaliana ecotype Col-0. The screening showed that the promising candidates could be $\mathrm{PIP}_{2}$-dependent isoforms from the PLD $\beta$, PLD $\gamma$ and PLD $\zeta$ families (Figure 7). We can speculate that they could be connected with the above mentioned PI4K activity, producing precursor for $\mathrm{PIP}_{2}$ biosynthesis. The evidence that PLD isoforms exhibit redundant effect upon Pseudomonas syrigae infection was provided recently by Johansson et al. (2014).

\section{METABOLOMIC SCREENING}

The aim of this part of our study was to find the metabolic compounds, which are affected by $n$-butanol and involved in the SA pathway. For this purpose, we used the mass spectrometrybased metabolomic fingerprinting described by Vaclavik et al. (2013). A very important output from the screening is the evidence that $t$-butanol treatment, used in our study (but also by other researchers studying PLD function) as a negative control to $n$-butanol, is really biologically "inactive." This is based on the fact that the PCA analysis of the samples determined no differences between control samples vs. $t$-butanol and the SA treated samples vs. $t$-butanol (i.e., their metabolomes were similar). On the other hand, the samples treated with $n$-butanol clustered very well (Figure 5). We were able to identify several characteristic metabolites for the samples treated with $n$-butanol. We were also able to predict the molecular formulas and we proposed their tentative identification (Table 1). It is not surprising that a higher amount of SA and SA-hexoside was found in the samples treated by SA. In fact, we were able to identify only a few metabolites affected by SA, probably due to the relatively short time of treatment. It was shown that BTH causes significant alterations in metabolome $24 \mathrm{~h}$ after treatment, while after $4 \mathrm{~h}$ the changes were much less 


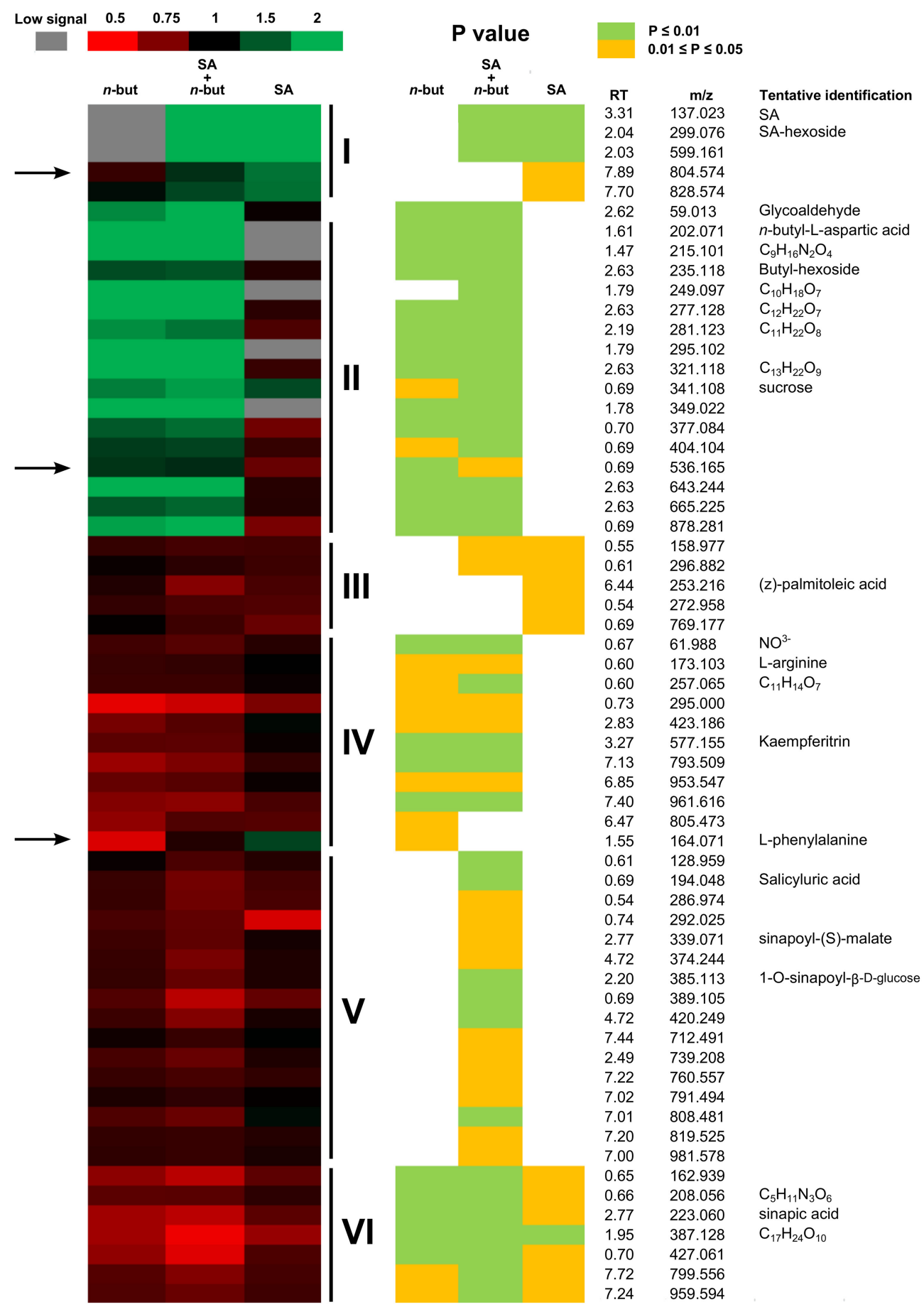

FIGURE 6 | Heat map of metabolites. Ten-day-old Arabidopsis thaliana seedlings were treated for $6 \mathrm{~h}$ with $0.1 \% n$-butanol or with $50 \mu \mathrm{M} \mathrm{NaSA}$ (SA) and both chemicals together. Fresh MS was used as a control. The Heat map values represent a ratio between the treated and control samples (treatment/control). The green color indicates increased values, red indicates decreased values and black indicates zero; see the color scale. The gray color indicates metabolites with a low signal in particular treated samples. $P$-value is represented by yellow $0.01<P<0.05$; bright green $P<0.01$ (Student's $t$-test). The arrows indicate putative metabolites with a similar pattern of response to treatment as the $P R-1$ gene transcription. Group I represents metabolites induced by SA. Group II represents metabolites induced by n-butanol. Group III represents metabolites suppressed by SA. Group IV represents metabolites suppressed by $n$-butanol. Group $\vee$ represents metabolites suppressed only when SA and n-butanol were applied together. Group VI represents metabolites suppressed by all treatments. This experiment was repeated in three biological repeats with similar results. RT, retention time; $m / z$, mass to charge ratio. 


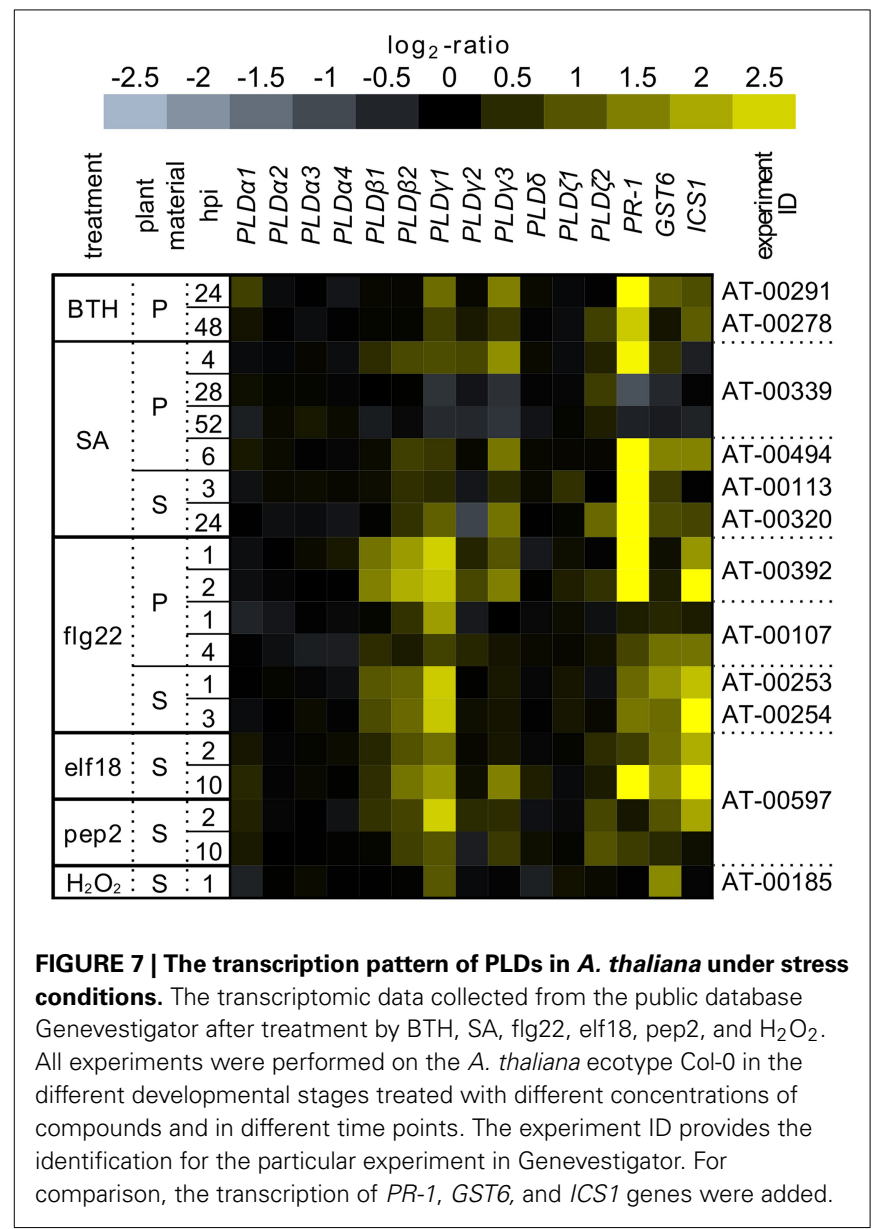

significant (Hien Dao et al., 2009). We chose the $6 \mathrm{~h}$ time-point to get the information in the same time frame as we used for the transcriptional study (Figure 1). Interestingly, $n$-butanol had a higher impact on the A. thaliana metabolome compared to the SA treatment. Seventeen metabolites were affected by SA and 34 by $n$-butanol (Figure 6).

We were able to predict structure for several metabolites that changed upon treatment. The heat map representing the changes of 61 metabolites supplemented with RT-m/z and the putative names of several predicted compounds is shown in Figure 6. Interestingly, the behavior of phenylalanine, a precursor of SA biosynthesis, exhibits a similar pattern as $P R-1$ transcription upon treatment. Another two compounds exhibit patterns similar to PR-1 (RT_m/z 7.89_804.5 and 0.69_536.1; Figure 6). These compounds could be interesting targets of further research.

\section{CONCLUSION}

The observations were summarized in the scheme presented in Figure 8. $n$-butanol affects $P R-1$ transcription and NPR1 accumulation in the nucleus in the presence of SA. We propose that our current study should be a new puzzle fitting in the previous idea that PA produced by PLD is involved in the SA signaling pathway as $n$-butanol alters PLD activity. We found 61 metabolites whose levels were changed upon the treatment with $n$-butanol and SA. We showed that the $n$-butanol treatment has

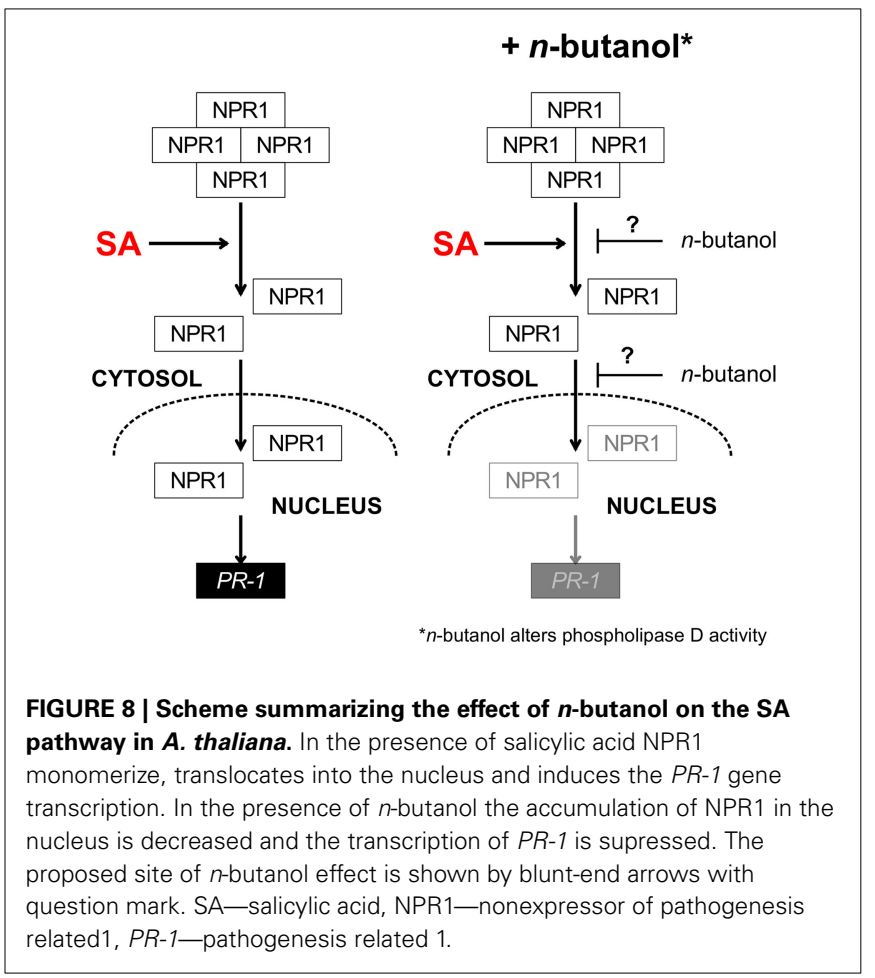

a higher impact on the metabolome than treatment with SA. We provided the metabolomic evidence that $t$-butanol can be really used as a negative control in studies using $n$-butanol.

\section{AUTHOR CONTRIBUTIONS}

Martin Janda created the conception and design, performed and analyzed the experiments and also composed the manuscript. Vladimír Šašek designed, performed and analyzed the experiments. Jan Andrejch performed and analyzed the confocal microscopy experiments. Hana Chmelar̆ová performed and analyzed the experiments (metabolomic screening). Miroslava Nováková performed and analyzed the experiments (confocal microscopy) and critically revised the manuscript. Jana Hajšlová analyzed the data (metabolomic screening) and critically revised the manuscript. Lenka Burketová critically revised the manuscript. Olga Valentová created the conception, critically revised the manuscript and also composed the manuscript. All authors concurred in the final version of the manuscript.

\section{ACKNOWLEDGMENTS}

We would like to thank Myrta Pařízková for her excellent technical support and also to Bc. Lucie Lamparová for her support. This work was supported by the Czech Science Foundation grants nos. 501/11/1654 and from specific university research (MSMT No 21/2015). Martin Janda would like to thank associate professor Zuzana Novotná for her supervising during master study. Martin Janda also want to thank to Dr. Kenichi Tsuda from Max Planck Institute of Plant Breeding Research and Lucie Trdá PhD. for providing advices during research. Special thanks belong to professor Xinnian Dong from Duke University, who kindly provided us the 
seeds of 35S::NPR1-GFP, 35S::npr1C82A-GFP, 35S::npr1C216AGFP. The authors express their thanks to the developers of open source software used in the preparation of this study, particularly Gimp and Inkscape.

\section{SUPPLEMENTARY MATERIAL}

The Supplementary Material for this article can be found online at: http://www.frontiersin.org/journal/10.3389/fpls.2015. 00059/abstract

\section{REFERENCES}

Blanco, F., Salinas, P., Cecchini, N. M., Jordana, X., Van Hummelen, P., Alvarez, M. E., et al. (2009). Early genomic responses to salicylic acid in Arabidopsis. Plant Mol. Biol. 70, 79-102. doi: 10.1007/s11103-009-9458-1

Cao, H., Bowling, S. A., Gordon, A. S., and Dong, X. N. (1994). Characterization of an Arabidopsis mutant that is nonresponsive to inducers of systemic acquiredresistance. Plant Cell 6, 1583-1592.

Clay, N. K., Adio, A. M., Denoux, C., Jander, G., and Ausubel, F. M. (2009). Glucosinolate metabolites required for an Arabidopsis innate immune response. Science 323, 95-101. doi: 10.1126/science.1164627

Czechowski, T., Stitt, M., Altmann, T., Udvardi, M. K., and Scheible, W.-R. (2005). Genome-wide identification and testing of superior reference genes for transcript normalization in Arabidopsis. Plant Physiol. 139, 5-17. doi: 10.1104/pp.105.063743

De Torres Zabela, M., Fernandez-Delmond, I., Niittyla, T., Sanchez, P., and Grant, M. (2002). Differential expression of genes encoding Arabidopsis phospholipases after challenge with virulent or avirulent Pseudomonas isolates. Mol. Plant Microbe Interact. 15, 808-816. doi: 10.1094/MPMI.2002.15.8.808

Dhonukshe, P., Laxalt, A. M., Goedhart, J., Gadella, T. W., and Munnik, T. (2003). Phospholipase d activation correlates with microtubule reorganization in living plant cells. Plant Cell 15, 2666-2679. doi: 10.1105/tpc.014977

Fu, Z. Q., Yan, S., Saleh, A., Wang, W., Ruble, J., Oka, N., et al. (2012). NPR3 and NPR4 are receptors for the immune signal salicylic acid in plants. Nature 486, 228-232. doi: 10.1038/nature11162

Gardiner, J., Collings, D. A., Harper, J. D., and Marc, J. (2003). The effects of the phospholipase D-antagonist 1-butanol on seedling development and microtubule organisation in Arabidopsis. Plant Cell Physiol. 44, 687-696. doi: $10.1093 / \mathrm{pcp} / \mathrm{pcg} 095$

Glazebrook, J. (2005). Contrasting mechanisms of defense against biotrophic and necrotrophic pathogens. Annu. Rev. Phytopathol. 43, 205-227. doi: 10.1146/annurev.phyto.43.040204.135923

Hien Dao, T. T., Puig, R. C., Kim, H. K., Erkelens, C., Lefeber, A. W., Linthorst, H. J., et al. (2009). Effect of benzothiadiazole on the metabolome of Arabidopsis thaliana. Plant Physiol. Biochem. 47, 146-152. doi: 10.1016/j.plaphy.2008.10.001

Hirase, A., Hamada, T., Itoh, T. J., Shimmen, T., and Sonobe, S. (2006). n-Butanol induces depolymerization of microtubules in vivo and in vitro. Plant Cell Physiol. 47, 1004-1009. doi: 10.1093/pcp/pcj055

Hruz, T., Laule, O., Szabo, G., Wessendorp, F., Bleuler, S., Oertle, L., et al. (2008). Genevestigator v3: a reference expression database for the meta-analysis of transcriptomes. Adv. Bioinformatics 2008:420747. doi: 10.1155/2008/420747

Jakoby, M., Weisshaar, B., Droge-Laser, W., Vicente-Carbajosa, J., Tiedemann, J., Kroj, T., et al. (2002). bZIP transcription factors in Arabidopsis. Trends Plant Sci. 7, 106-111. doi: 10.1016/S1360-1385(01)02223-3

Janda, M., Planchais, S., Djafi, N., Martinec, J., Burketova, L., Valentova, O., et al. (2013). Phosphoglycerolipids are master players in plant hormone signal transduction. Plant Cell Rep. 32, 839-851. doi: 10.1007/s00299-013-1399-0

Janda, M., and Ruelland, E. (2014). Magical mystery tour: salicylic acid signalling. Environ. Exp. Bot. doi: 10.1016/j.envexpbot.2014.07.003. (in press).

Johansson, O. N., Fahlberg, P., Karimi, E., Nilsson, A. K., Ellerström, M., and Andersson, M. X. (2014). Redundancy among phospholipase D isoforms in resistance triggered by recognition of the Pseudomonas syringae effector AvrRpml in Arabidopsis thaliana. Front. Plant Sci. 5:639. doi: 10.3389/fpls.2014.00639

Kalachova, T., Lakovenko, O., Kretinin, S., and Kravets, V. (2013). Involvement of phospholipase D and NADPH-oxidase in salicylic acid signaling cascade. Plant Physiol. Biochem. 66, 127-133. doi: 10.1016/j.plaphy.2013.02.006
Kalachova, T. A., Iakovenko, O. M., Kretinin, S. V., and Kravets, V. S. (2012). Effects of salicylic and jasmonic acid on Phospholipase D activity and the level of active oxygen species in soybean seedlings. Biochemistry (Moscow) 29, 169-176. doi: 10.1134/S1990747812030099

Kim, K. C., Lai, Z., Fan, B., and Chen, Z. (2008). Arabidopsis WRKY38 and WRKY62 transcription factors interact with histone deacetylase 19 in basal defense. Plant Cell 20, 2357-2371. doi: 10.1105/tpc.107.055566

Kinkema, M., Fan, W. H., and Dong, X. N. (2000). Nuclear localization of NPR1 is required for activation of PR gene expression. Plant Cell 12, 2339-2350. doi: 10.1105/tpc.12.12.2339

Krinke, O., Ruelland, E., Valentova, O., Vergnolle, C., Renou, J. P., Taconnat, L., et al. (2007). Phosphatidylinositol 4-kinase activation is an early response to salicylic acid in arabidopsis suspension cells. Plant Physiol. 144, 1347-1359. doi: 10.1104/pp.107.100842

Krinke, O., Flemr, M., Vergnolle, C., Collin, S., Renou, J. P., Taconnat, L., et al. (2009). Phospholipase D activation is an early component of the salicylic acid signaling pathway in Arabidopsis cell suspensions. Plant Physiol. 150, 424-436. doi: 10.1104/pp.108.133595

Lee, S. M., Suh, S., Kim, S., Crain, R. C., Kwak, J. M., Nam, H. G., et al. (1997). Systemic elevation of phosphatidic acid and lysophospholipid levels in wounded plants. Plant J. 12, 547-556. doi: 10.1046/j.1365-313X.1997.00547.x

Liscovitch, M., Czarny, M., Fiucci, G., and Tang, X. (2000). Phospholipase D: molecular and cell biology of a novel gene family. Biochem. J. 345( $\mathrm{Pt} \mathrm{3}$ ), 401-415. doi: 10.1042/0264-6021:3450401

Marshall, O. J. (2004). PerlPrimer: cross-platform, graphical primer design for standard, bisulphite and real-time PCR. Bioinformatics 20, 2471-2472. doi: 10.1093/bioinformatics/bth254

Matouskova, J., Janda, M., Fiser, R., Sasek, V., Kocourkova, D., Burketova, L., et al. (2014). Changes in actin dynamics are involved in salicylic acid signaling pathway. Plant Sci. 223, 36-44. doi: 10.1016/j.plantsci.2014.03.002

McGee, J. D., Roe, J. L., Sweat, T. A., Wang, X. M., Guikema, J. A., and Leach, J. E. (2003). Rice phospholipase D isoforms show differential cellular location and gene induction. Plant Cell Physiol. 44, 1013-1026. doi: 10.1093/pcp/pcg125

Motes, C. M., Pechter, P., Yoo, C. M., Wang, Y. S., Chapman, K. D., and Blancaflor, E. B. (2005). Differential effects of two phospholipase D inhibitors, 1-butanol and $\mathrm{N}$-acylethanolamine, on in vivo cytoskeletal organization and Arabidopsis seedling growth. Protoplasma 226, 109-123. doi: 10.1007/s00709-0050124-4

Mou, Z., Fan, W., and Dong, X. (2003). Inducers of plant systemic acquired resistance regulate NPR1 function through redox changes. Cell 113, 935-944. doi: 10.1016/S0092-8674(03)00429-X

Munnik, T., Arisz, S. A., De Vrije, T., and Musgrave, A. (1995). G Protein activation stimulates phospholipase D signaling in plants. Plant Cell 7, 2197-2210. doi: 10.1105/tpc.7.12.2197

Novakova, M., Sasek, V., Dobrev, P. I., Valentova, O., and Burketova, L. (2014). Plant hormones in defense response of Brassica napus to Sclerotinia sclerotiorum - reassessing the role of salicylic acid in the interaction with a necrotroph. Plant Physiol. Biochem. 80, 308-317. doi: 10.1016/j.plaphy.2014.04.019

Pleskot, R., Pejchar, P., Bezvoda, R., Lichtscheidl, I. K., Wolters-Arts, M., Marc, J. et al. (2012). Turnover of phosphatidic acid through distinct signaling pathways affects multiple aspects of pollen tube growth in tobacco. Front. Plant Sci. 3:54. doi: 10.3389/fpls.2012.00054

Pleskot, R., Pejchar, P., Staiger, C. J., and Potocky, M. (2014). When fat is not bad: the regulation of actin dynamics by phospholipid signaling molecules. Front. Plant Sci. 5:5. doi: 10.3389/fpls.2014.00005

Pleskot, R., Potocky, M., Pejchar, P., Linek, J., Bezvoda, R., Martinec, J., et al. (2010). Mutual regulation of plant phospholipase D and the actin cytoskeleton. Plant J. 62, 494-507. doi: 10.1111/j.1365-313X.2010.04168.x

Potocky, M., Elias, M., Profotova, B., Novotna, Z., Valentova, O., and Zarsky, V. (2003). Phosphatidic acid produced by phospholipase D is required for tobacco pollen tube growth. Planta 217, 122-130. doi: 10.1007/s00425-002-0965-4

Potocky, M., Pleskot, R., Pejchar, P., Vitale, N., Kost, B., and Zarsky, V. (2014). Live-cell imaging of phosphatidic acid dynamics in pollen tubes visualized by Spo20p-derived biosensor. New Phytol. 203, 483-494. doi: 10.1111/nph. 12814

Profotova, B., Burketova, L., Novotna, Z., Martinec, J., and Valentova, O. (2006). Involvement of phospholipases $\mathrm{C}$ and $\mathrm{D}$ in early response to SAR and ISR inducers in Brassica napus plants. Plant Physiol. Biochem. 44, 143-151. doi: 10.1016/j.plaphy.2006.02.003 
Rainteau, D., Humbert, L., Delage, E., Vergnolle, C., Cantrel, C., Maubert, M. A., et al. (2012). Acyl Chains of Phospholipase D transphosphatidylation products in arabidopsis cells: a study using multiple reaction monitoring mass spectrometry. PLoS ONE 7:e41985. doi: 10.1371/journal.pone.0041985

Ritchie, S., and Gilroy, S. (1998). Abscisic acid signal transduction in the barley aleurone is mediated by phospholipase D activity. Proc. Natl. Acad. Sci. U.S.A. 95, 2697-2702. doi: 10.1073/pnas.95.5.2697

Sasek, V., Janda, M., Delage, E., Puyaubert, J., Guivarc'h, A., Lopez Maseda, E., et al. (2014). Constitutive salicylic acid accumulation in pi4kIIIbetalbeta2 Arabidopsis plants stunts rosette but not root growth. New Phytol. 203, 805-816. doi: $10.1111 /$ nph. 12822

Sasek, V., Novakova, M., Jindrichova, B., Boka, K., Valentova, O., and Burketova, L. (2012). Recognition of avirulence gene AvrLml from hemibiotrophic ascomycete Leptosphaeria maculans triggers salicylic acid and ethylene signaling in Brassica napus. Mol. Plant Microbe Interact. 25, 1238-1250. doi: 10.1094/MPMI-02-12-0033-R

Spoel, S. H., Mou, Z. L., Tada, Y., Spivey, N. W., Genschik, P., and Dong, X. N. A. (2009). Proteasome-mediated turnover of the transcription coactivator NPR1 plays dual roles in regulating plant immunity. Cell 137, 860-872. doi: 10.1016/j.cell.2009.03.038

Thiery, L., Leprince, A. S., Lefebvre, D., Ghars, M. A., Debarbieux, E., and Savoure, A. (2004). Phospholipase D is a negative regulator of proline biosynthesis in Arabidopsis thaliana. J. Biol. Chem. 279, 14812-14818. doi: 10.1074/jbc.M308456200

Tsuda, K., and Katagiri, F. (2010). Comparing signaling mechanisms engaged in pattern-triggered and effector-triggered immunity. Curr. Opin. Plant Biol. 13, 459-465. doi: 10.1016/j.pbi.2010.04.006

Tsuda, K., Sato, M., Glazebrook, J., Cohen, J. D., and Katagiri, F. (2008). Interplay between MAMP-triggered and SA-mediated defense responses (vol 53, pg 763, 2008). Plant J. 55, 1061-1061. doi: 10.1111/j.1365-313X.2008.03589.x

Vaclavik, L., Mishra, A., Mishra, K. B., and Hajslova, J. (2013). Mass spectrometrybased metabolomic fingerprinting for screening cold tolerance in Arabidopsis thaliana accessions. Anal. Bioanal. Chem. 405, 2671-2683. doi: 10.1007/s00216012-6692-1

Vlot, A. C., Dempsey, D. A., and Klessig, D. F. (2009). Salicylic Acid, a multifaceted hormone to combat disease. Annu. Rev. Phytopathol. 47, 177-206. doi: 10.1146/annurev.phyto.050908.135202

Wang, D., Weaver, N. D., Kesarwani, M., and Dong, X. (2005). Induction of protein secretory pathway is required for systemic acquired resistance. Science 308, 1036-1040. doi: 10.1126/science.1108791

Wildermuth, M. C., Dewdney, J., Wu, G., and Ausubel, F. M. (2001). Isochorismate synthase is required to synthesize salicylic acid for plant defence. Nature 414, 562-565. doi: $10.1038 / 35107108$
Yang, S. F., Freer, S., and Benson, A. A. (1967). Transphosphatidylation by Phospholipase D. J. Biol. Chem. 242, 477.

Yao, H., Wang, G., Guo, L., and Wang, X. (2013). Phosphatidic acid interacts with a MYB transcription factor and regulates its nuclear localization and function in Arabidopsis. Plant Cell 25, 5030-5042. doi: 10.1105/tpc.113.120162

Young, S. A., Wang, X. M., and Leach, J. E. (1996). Changes in the plasma membrane distribution of rice phospholipase $\mathrm{D}$ during resistant interactions with Xanthomonas oryzae pv oryzae. Plant Cell 8, 1079-1090.

Zhang, K., Halitschke, R., Yin, C., Liu, C. J., and Gan, S. S. (2013). Salicylic acid 3-hydroxylase regulates Arabidopsis leaf longevity by mediating salicylic acid catabolism. Proc. Natl. Acad. Sci. U.S.A. 110, 14807-14812. doi: 10.1073/pnas.1302702110

Zhang, X., Chen, S., and Mou, Z. (2010). Nuclear localization of NPR1 is required for regulation of salicylate tolerance, isochorismate synthase 1 expression and salicylate accumulation in Arabidopsis. J. Plant Physiol. 167, 144-148. doi: 10.1016/j.jplph.2009.08.002

Zhang, Y. L., Fan, W. H., Kinkema, M., Li, X., and Dong, X. N. (1999). Interaction of NPR1 with basic leucine zipper protein transcription factors that bind sequences required for salicylic acid induction of the PR-1 gene. Proc. Natl. Acad. Sci. U.S.A. 96, 6523-6528. doi: 10.1073/pnas.96.11.6523

Zhao, J., Devaiah, S. P., Wang, C. X., Li, M. Y., Welti, R., and Wang, X. M. (2013). Arabidopsis phospholipase D1 modulates defense responses to bacterial and fungal pathogens. New Phytol. 199, 228-240. doi: 10.1111/Nph.12256

Conflict of Interest Statement: The authors declare that the research was conducted in the absence of any commercial or financial relationships that could be construed as a potential conflict of interest.

Received: 04 November 2014; accepted: 22 January 2015; published online: 18 February 2015.

Citation: Janda $M$, Šašek V, Chmelařová $H$, Andrejch J, Nováková M, Hajšlová J, Burketová L and Valentová O (2015) Phospholipase D affects translocation of NPRI to the nucleus in Arabidopsis thaliana. Front. Plant Sci. 6:59. doi: 10.3389/fpls. 2015.00059

This article was submitted to Plant-Microbe Interaction, a section of the journal Frontiers in Plant Science.

Copyright (ㅇ 2015 Janda, Šašek, Chmelařová, Andrejch, Nováková, Hajšlová, Burketová and Valentová. This is an open-access article distributed under the terms of the Creative Commons Attribution License (CC BY). The use, distribution or reproduction in other forums is permitted, provided the original author(s) or licensor are credited and that the original publication in this journal is cited, in accordance with accepted academic practice. No use, distribution or reproduction is permitted which does not comply with these terms. 